\title{
Prophylaxis for infective endocarditis: antibiotic sensitivity of dental plaque
}

\author{
TW MACFARLANE, ${ }^{*}$ DA McGOWAN, $\dagger \mathrm{K}$ HUNTER,‡ D MACKENZIE* \\ From the *Oral Microbiology Unit and the †Department of Oral Surgery, Dental Hospital and School, \\ Glasgow, G2 3JZ, Scotland, and the $\ddagger$ Department of Oral Medicine and Oral Surgery, School of Dentistry, \\ Dunedin, New Zealand
}

SUMMARY The antibiotic sensitivity pattern of bacteria isolated from bacteraemia after dental extraction was compared with that of bacteria isolated from dental plaque samples from the same patient. The results supported the current practice of using penicillin and erythromycin empirically for prophylaxis. The prediction of the most appropriate antibiotic for prophylaxis using dental plaque samples was most accurate when the minimum inhibitory concentration (MIC) of plaque isolates were used. It appears that a predictive test using dental plaque may be of some value in patients with recent or long-term antibiotic therapy.

A relation between dental extractions and infective endocarditis has been recognised for many years, ${ }^{1}$ and patients at risk are protected during treatment by prophylactic antibiotic administration. Antibiotic regimens, for example those recommended by the American Heart Assocation, although based on available clinical knowledge and experimental data, are still empirical. However, it has been claimed that rational prophylaxis can be achieved if the antibiotic sensitivity of dental plaque from the area where surgery is proposed is assessed in vitro. ${ }^{23}$ Since the accuracy of this approach has received little investigation, we decided to examine the value of this procedure as a means of predicting the antibiotic most suitable for prophylaxis in a specific patient.

\section{Materials and methods}

Patients attending the Department of Oral Surgery in Glasgow Dental Hospital and School for tooth extraction were asked to participate in this study. The study was approved by the Area Ethics Committee, and subjects were required to give their consent. Patients who were between 20-50 yrs, had a normal medical history and required an uncomplicated extraction of a single lower first or second molar under local anaesthetic, were included. Any patient who gave a history of antibiotic therapy during the previous three months or who worked in a hospital was excluded.
After local anaesthesia, a sterile dental "plastic" filling instrument (Ash) was used to remove dental plaque from the buccal and lingual crevices of the tooth to be extracted. Using a sterile disposable plastic loop (Nunc, Denmark) $0 \cdot 1 \mathrm{ml}$ of plaque from each sample was added to $1 \mathrm{ml}$ of sterile peptone water (Oxoid). The skin of the anticubital fossa was prepared with soap and alcoholic hibitane before tooth extraction. Venous blood $(10 \mathrm{ml})$ was removed within five minutes of commencement of tooth extraction. Half of the blood sample was inoculated into Brain Heart Infusion broth (Gibco-Europe) for aerobic culture, and the remaining $5 \mathrm{ml}$ inoculated into $50 \mathrm{ml}$ of thioglycollate broth with haemin and menadione (Gibco-Europe) for anaerobic culture. The samples of plaque and the blood cultures were sent immediately to the Oral Microbiology Unit in the Dental Hospital.

Table 1 Antibiotic concentrations used in disc diffusion tests and MIC assays

\begin{tabular}{lcl}
\hline & $\begin{array}{l}\text { Disc } \\
\text { concentration }(\mu g)\end{array}$ & $\begin{array}{l}\text { MIC range of } \\
\text { concentrations }(\mathrm{mg} / \mathrm{l})\end{array}$ \\
\hline Penicillin G & 1 Unit & $0 \cdot 15-4 \cdot 00$ \\
Ampicillin & 2 & $0 \cdot 12-8 \cdot 00$ \\
Erythromycin & 5 & $0 \cdot 06-8 \cdot 00$ \\
Cephaloridine & 5 & $0 \cdot 12-16 \cdot 00$ \\
Tetracycline & 25 & $0 \cdot 06-4 \cdot 00$ \\
Clindamycin & 2 & $0 \cdot 06-4 \cdot 00$ \\
Streptomycin & 10 & $0 \cdot 05-32 \cdot 00$ \\
Vancomycin & 2 & $0 \cdot 1-25 \cdot 00$ \\
\hline
\end{tabular}


Table 2 Concentration of antibiotic expected in blood after prophylaxis, which was used in the study to classify isolates as sensitive or resistant

\begin{tabular}{|c|c|c|c|c|c|}
\hline \multirow[t]{2}{*}{ Antibiotic } & \multicolumn{3}{|c|}{ Approximate adult prophylactic treatment } & \multirow{2}{*}{$\begin{array}{l}\text { Expected blood } \\
\text { concentration }(\mathrm{mg} / \mathrm{l}) \\
\text { (h) }\end{array}$} & \multirow{2}{*}{$\begin{array}{l}\text { Blood concentration } \\
\text { used in study (mg/l) }\end{array}$} \\
\hline & Dose (mg) & Administered & Time before surgery $(h)$ & & \\
\hline Penicillin G & 600 & IM & $1 / 2$ & $7 \cdot 2$ & $2 \cdot 0$ \\
\hline Ampicillin & 500 & Oral & 2 & $2 \cdot 5$ & $1 \cdot 0$ \\
\hline Erythromycin & 500 & Oral & $1-2$ & $1 \cdot 5$ & 0.5 \\
\hline Cephaloridine & 500 & IM & 1 & 15 & $4 \cdot 0$ \\
\hline Tetracyline & 500 & Oral & 4 & 3 & $1 \cdot 0$ \\
\hline Clindamycin & 500 & Oral & $1-2$ & $3 \cdot 5$ & $1 \cdot 0$ \\
\hline Streptomycin & 500 & IM & 1 & 32 & $8 \cdot 0$ \\
\hline Vancomycin & 1000 & IV & 1 & 25 & $5 \cdot 0$ \\
\hline
\end{tabular}

Table 3 Identity of 22 isolates from blood cultures following dental bacteraemia and of the 36 resistant/moderately resistant isolates from dental plaque

\begin{tabular}{lcc}
\hline & $\begin{array}{l}\text { Blood culture } \\
(15)\end{array}$ & $\begin{array}{l}\text { Dental plaque } \\
(15)\end{array}$ \\
\hline Streptococcus mutans & 4 & 5 \\
Streptococcus salivarius & 3 & 3 \\
Streptococcus sanguis & 4 & 6 \\
Streptococcus mitior & 3 & 10 \\
Streptococcus milleri & 1 & 0 \\
Beta-haemolytic streptococci & 4 & 5 \\
Anaerobic streptococci & 2 & 3 \\
Veillonella spp & 1 & 4 \\
& $22^{*}$ & $36 \dagger$ \\
\hline
\end{tabular}

*In 10 blood cultures one species was present, in three cultures two species, and in two cultures three species were isolated.

$\dagger$ In one plaque sample one resistant/moderately resistant species was present, in seven samples two species, and in seven samples three species were isolated.

\section{BLOOD CULTURE}

The blood cultures were incubated at $37^{\circ} \mathrm{C}$ and subcultured on days 2,4 and 7 after initial collection. Aliquots $(0.1 \mathrm{ml})$ were transferred to $10 \%$ horse blood agar (Gibco-Europe), plated out for separate colonies and incubated under aerobic, anaerobic and $10 \% \mathrm{CO}_{2}$ conditions. Pure cultures of all bacteria isolated were prepared and identified using standard techniques. The antibiotic sensitivity of each isolated was assessed using the Stokes method, ${ }^{4}$ and the MIC calculated by agar dilution techniques. The antibiotics tested and the disc strengths used are shown in Table 1.

\section{PLAQUE SAMPLES}

The plaque samples in peptone water were dispersed using a Whirlimixer (Fisons, Loughborough) $\rightarrow$ for one minute. Direct antibiotic sensitivity tests of using Stokes' method ${ }^{4}$ were performed by inoculat- 6 ing $2 \mu \mathrm{l}$ of the plaque suspension on to $10 \%$ horse $\frac{}{5}$ blood agar plates (Gibco-Europe). Staphylococcus aureus NCTC 6571 was used as the control organ- $\frac{7}{2}$ ism. The antibiotics tested and the disc strengths used are shown in Table 1 . The plates were incu- $\vec{\bullet}$ bated at $37^{\circ} \mathrm{C}$ for $18 \mathrm{~h}$ aerobically and anaerobically and the result read. A selection of resistant and 0 moderately resistant organisms were removed, pure cultures obtained and identified using standard techniques. These cultures were then retested using Stokes' method. Finally, the MIC of the resistant/ moderately resistant bacteria were assessed using an agar dilution method.

Bacteria were inoculated from blood agar cultures into Eugon broth (BBL Maryland, USA) and incubated at $37^{\circ} \mathrm{C}$ for $6 \mathrm{~h}$. The resulting growth was adjusted with sterile normal saline to give a suspen- $\frac{8}{0}$ sion containing approximately $10^{4} \mathrm{CFU} / \mathrm{ml}$ when added to the antibiotic sensitivity plates. In the case of anaerobic bacteria, colonies were scraped from blood agar plates, added to $1 \%$ peptone water (Oxoid) and agitated using a Whirlimixer for $30 \mathrm{~s}$ 옥 (Fisons, Loughborough). The resulting suspension $\rightarrow$ was adjusted to give approximately $10^{4} \mathrm{CFU} / \mathrm{ml}$. when added to the antibiotic sensitivity plates. The $N$

Table 4 The MICs of blood cultures and dental plaque isolates compared with approximately one quarter of the expected blood concentration of antibiotic following a prophylactic dose

\begin{tabular}{|c|c|c|c|c|}
\hline & \multicolumn{2}{|c|}{22 blood culture isolates } & \multicolumn{2}{|c|}{36 dental plaque isolates } \\
\hline & $\begin{array}{l}\text { No sensitive to } 1 / 4 \text { of } \\
\text { expected blood level }\end{array}$ & $\begin{array}{l}\text { No resistant to } 1 / 4 \text { of } \\
\text { expected blood level }\end{array}$ & $\begin{array}{l}\text { No sensitive to } 1 / 4 \text { of } \\
\text { expected blood level }\end{array}$ & $\begin{array}{l}\text { No resistant to } 1 / 4 \text { of } \\
\text { expected blood level }\end{array}$ \\
\hline $\begin{array}{l}\text { Penicillin G } \\
\text { Ampicillin } \\
\text { Erythromycin } \\
\text { Cephaloridine } \\
\text { Tetracycline } \\
\text { Clindamycin } \\
\text { Streptomycin } \\
\text { Vancomycin }\end{array}$ & $\begin{array}{r}22 \\
20 \\
22 \\
22 \\
1 \\
22 \\
1 \\
22\end{array}$ & $\begin{array}{r}0 \\
2 \\
0 \\
0 \\
21 \\
0 \\
21 \\
0\end{array}$ & $\begin{array}{r}36 \\
34 \\
31 \\
35 \\
2 \\
36 \\
4 \\
30\end{array}$ & $\begin{array}{r}0 \\
2 \\
5 \\
1 \\
34 \\
0 \\
32 \\
6\end{array}$ \\
\hline
\end{tabular}


Table 5 Suitability of each antibiotic if used blindly in prophylaxis: a comparison of the MICs of the blood culture isolates and one quarter of the expected blood concentration of antibiotic were used as the criterion for success or failure of prophylaxis.

\begin{tabular}{llc}
\hline & $\begin{array}{l}\text { No of correct } \\
\text { choices }\end{array}$ & $\begin{array}{l}\text { No of wrong } \\
\text { choices }\end{array}$ \\
\hline Penicillin G & 15 & 0 \\
Ampicillin & 13 & 2 \\
Erythromycin & 15 & 0 \\
Cephaloridine & 15 & 0 \\
Tetracycline & 0 & 15 \\
Clindamycin & 15 & 0 \\
Streptomycin & 0 & 15 \\
Vancomycin & 15 & 0 \\
\hline
\end{tabular}

tests were performed on DST agar (Oxoid) with $10 \%$ lysed horse blood. The antibiotics tested and the range of concentrations used are shown in Table 1. The Adapad system produced by Mast Laboratories Ltd, Liverpool, was employed to produce antibiotic dilutions. The plates were inoculated with a multipoint inoculator and incubated for $18 \mathrm{~h}$ at $37^{\circ} \mathrm{C}$. The MIC was the lowest concentration of antibiotic that resulted in complete suppression of growth.
The MIC of each isolate was compared with approximately one quarter of the blood level of antibiotic expected from a prophylactic dose of each of the eight antibiotics studied, ${ }^{5}$ (Table 2). If the MIC of an isolate was equal to or less than one quarter of the expected blood level of antibiotic, the isolate was recorded as sensitive. Otherwise, isolates were recorded as resistant.

\section{Results}

Fifteen patients were included in the study. The species of bacteria isolated from blood cultures and the resistant and moderately resistant bacteria isolated from dental plaque samples are shown in Table 3. The MIC values of both groups of bacteria when compared with one quarter of the expected blood concentrations for the eight antibiotics investigated are shown in Table 4. Next we investigated the result obtained if each antibiotic was used blindly for prophylaxis using a comparison of the MICs of the blood culture isolates and one quarter of the expected blood level of antibiotic as the criteria for success or failure of prophylaxis (Table 5). The results obtained when the Stokes method was used

Table 6 The accuracy of predicting a suitable antibiotic for prophylaxis using the antibiotic sensitivity of dental plaque isolates as assessed by the Stokes method: a comparison of the MICs of the blood culture isolates and one quarter of the expected antibiotic blood concentration was used as the criterion for success or failure

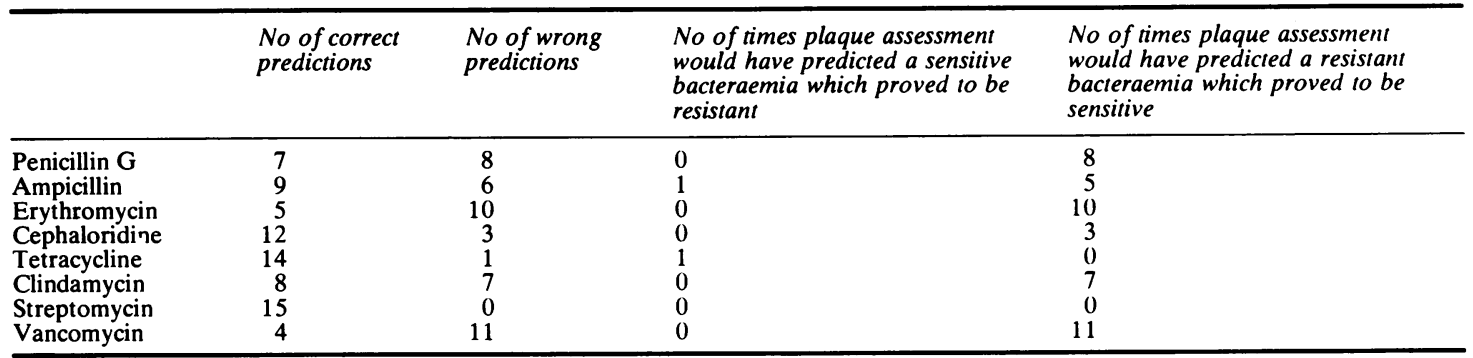

Table 7 The accuracy of predicting a suitable antibiotic for prophylaxis using the MIC results of dental plaque bacteria: $a$ comparison of the MICs of the blood culture isolates and one quarter of the expected antibiotic blood concentration were used as the criterion on success or failure

\begin{tabular}{|c|c|c|c|c|}
\hline & $\begin{array}{l}\text { No of correct } \\
\text { predictions }\end{array}$ & $\begin{array}{l}\text { No of wrong } \\
\text { predictions }\end{array}$ & $\begin{array}{l}\text { No of times plaque assessment } \\
\text { would have predicted a sensitive } \\
\text { bacteraemia which proved to be } \\
\text { resistant }\end{array}$ & $\begin{array}{l}\text { No of times plaque assessment } \\
\text { would have predicted a resistant } \\
\text { bacteraemia which proved to be } \\
\text { sensitive }\end{array}$ \\
\hline $\begin{array}{l}\text { Penicillin G } \\
\text { Ampicillin } \\
\text { Erythromycin } \\
\text { Cephaloridine } \\
\text { Tetracycline } \\
\text { Clindamycin } \\
\text { Streptomycin } \\
\text { Vancomycin }\end{array}$ & $\begin{array}{l}15 \\
10 \\
11 \\
14 \\
15 \\
15 \\
15 \\
11\end{array}$ & $\begin{array}{l}0 \\
5 \\
4 \\
1 \\
0 \\
0 \\
0 \\
4\end{array}$ & $\begin{array}{l}0 \\
2 \\
0 \\
0 \\
0 \\
0 \\
0 \\
0\end{array}$ & $\begin{array}{l}0 \\
3 \\
4 \\
1 \\
0 \\
0 \\
0 \\
4\end{array}$ \\
\hline
\end{tabular}


on dental plaque isolates to predict the correct antibiotic for prophylaxis following dental bacteraemia, are shown in Table 6 . The MICs of the blood culture isolates, compared with one quarter of the expected blood concentration, were used as the final criterion for a correct or inappropriate prediction.

The results obtained when the MICs of plaque bacteria were assayed and used to predict the correct drug for prophylaxis following dental bacteraemia are shown in Table 7. Again, the comparison of the MICs of the blood culture isolates and one quarter of the expected blood concentration of antibiotic was used as the final criterion for a correct or inappropriate choice.

\section{Discussion}

The results of this study support the current practice of using penicillin and erythromycin empirically for prophylaxis of patients at risk of developing infective endocarditis. All bacteria isolated from blood cultures and from plaque samples were sensitive to penicillin and all but five isolates from plaque were sensitive to erythromycin. With the exception of tetracycline and streptomycin, the other antibiotics tested also inhibited the growth of the majority of bacteraemia and plaque isolates. However, the accuracy of predicting the sensitivity of bacteraemia isolates by examining the antibiotic sensitivity pattern of dental plaque varied depending on the laboratory method used for assay. When the Stokes method was used to assess plaque sensitivity, penicillin would have been prescribed on seven of the 15 occasions when its use was indicated (Table 6) and erythromycin on five of the 15 occasions when its use was justified, using the criteria described earlier. If the MICs of the resistant dental plaque isolates were compared with the MIC values for the blood culture isolates, correlation between the groups of bacteria improved markedly for most antibiotics, especially penicillin, erythromycin, vancomycin and clindamycin (Table 7). The use of dental plaque antibiotic sensitivity results in prophylaxis tended to predict resistant bacteraemias which proved sensi- tive rather than predicting sensitive bacteraemias which proved resistant.

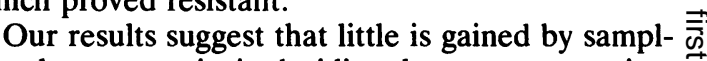
ing plaque to assist in deciding the most appropriate $\overrightarrow{0}$ antibiotic cover for patients at risk who have no 음 recent history of antibiotic therapy. In patients who are on long-term or recent antibiotic therapy, where $\mathbb{\nabla}$ a resistant flora may have developed, the assessment of antiobiotic plaque sensitivity of organisms may be

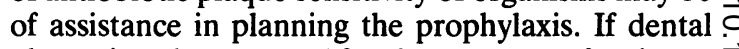
plaque is to be screened for the presence of resistant $\overrightarrow{\vec{\omega}}$ or moderately resistant bacteria, the MIC of any $\stackrel{\omega}{\sigma}$ such bacteria, which have been identified by Stokes' method, should be ascertained before advice con- $\omega$ cerning antibiotic prophylaxis is given. In fact it could be argued that it would be more appropriate to use the MBC of resistant strains found in plaque 0 when deciding on the most appropriate prophylactic 음 regimen.

Amoxycillin was not tested in our experiments $\frac{D}{2}$ since the antibiotic was not recommended for prophylaxis when this study was carried out. How- $\vec{\bullet}$ ever, it would be expected that amoxycillin would be at least as effective as ampicillin.

\section{References}

1 Okell CC, Elliot SD. Bacteraemia and oral sepsis. Lancet $\frac{\mathrm{Q}}{\mathrm{Q}}$ 1935;ii:869-72.

2 Drucker DB, Jolly M. Sensitivity of ora-micro-organisms to anti- $\overline{\mathrm{O}}$ biotics. Br Dent J 1971;131:442-4.

${ }^{3}$ Elliot RH, Dunbar JM. Antibiotic sensitivity of oral haemolytic streptococcus from children with congenital or acquired car- 0 diac disease. Br Dent $J$ 1977;142:283-5.

${ }^{4}$ Stokes EJ, Ridgway GL. Clinical bacteriology 5th ed. London:응 Edward Arnold, 1980:215-9.

${ }^{5}$ Wise R. Table of expected concentrations of antibiotic. In: Reeves DS, Philips I, Williams JD, Wise R, eds. Laboratory methods in antimicrobial therapy. Edinburgh: Livingstone, $\mathrm{O}$ 1978.

Requests for reprints to: Dr TW MacFarlane, Department of Oral Medicine and Pathology, Glasgow Dental Hospital N and School, 378 Sauchiehall Street, Glasgow G2 3JZ, Scotland. 